\title{
Mentale toestanden in de psychologie
}

\author{
Annemarie Kalis
}

\author{
ANTW 106 (3): 197-206
}

DOI: 10.5117/ANTW2014.3.KALI

\begin{abstract}
Mental states in psychology

Many of our thoughts, emotions and motivations have intentional content: they are 'about' something. In this paper I present my VENI research project, which starts from the observation that the everyday practice of empirical psychological research is built on the idea that mental states have content. However, empirical psychology lacks a clear view on how mental content should be understood and how mental states could be causally efficacious in virtue of their content. I focus on mental states that play a role in psychiatric symptomatology, and develop an interpretivist answer to these questions. I also offer some suggestions showing how an interpretivist notion of mental content could be used in empirical research on psychiatric symptoms.
\end{abstract}

Keywords: mental content, intentionality, mental causation, interpretivism, Davidson, psychiatry

\section{$1 \quad$ Inleiding}

Psychologie als discipline houdt zich bezig met de vraag waarom we doen wat we doen. En welke rol spelen mentale processen zoals gedachten, emoties en motivaties daarbij? Veel van de gedachten, emoties en motivaties waarin psychologen geïnteresseerd zijn, hebben intentionele inhoud: ze gaan ergens over. Om enkele voorbeelden te geven, de inhoudsopgave van het meest recente nummer van Psychological Bulletin toont een artikel over de invloed van de menstruatiecyclus op oordelen over mannelijke aantrekkelijkheid (Gildersleeve, Hasleton \& Fales 2014), en een studie waarin de hypothese is dat alcohol mensen sociaal vrijer maakt doordat 
het zorgen over afwijzing wegneemt (Fairbairn \& Sayette 2014). De mentale processen die in deze studies worden onderzocht, gaan ergens over. Namelijk over mannelijke aantrekkelijkheid, en over afwijzing. Het idee dat mentale toestanden intentionaliteit ofwel gerichtheid op een object bezitten, voert terug tot Franz Brentano (1874). Volgens Brentano was intentionaliteit zelfs het onderscheidende kenmerk van alle mentale toestanden. Dit is nog altijd een belangrijke discussie in de philosophy of mind, en hoewel velen menen dat er ook mentale toestanden zijn die niet ergens over gaan (zoals pijn of bepaalde emoties, zie bijvoorbeeld Searle 1983), wordt intentionaliteit nog altijd gezien als een centraal aspect van het mentale.

In de empirische psychologie wordt dus veelvuldig naar de intentionele inhoud van mentale toestanden verwezen. Maar belangrijker nog, in veel psychologisch onderzoek wordt impliciet aangenomen dat deze inhoud een causale rol speelt. Men zou zelfs kunnen stellen dat een groot deel van de psychologische onderzoekspraktijk volledig leunt op het idee van mentale veroorzaking. In bijvoorbeeld genoemde studie naar alcohol (Fairbairn \& Sayette 2014) wordt de hypothese verdedigd dat alcohol zorgen over afwijzing wegneemt, wat tot gevolg heeft dat mensen zich sociaal vrijer gaan gedragen. Hieronder ligt een vooronderstelling over de causale rol van zorgen over afwijzing: 'Social rejection concerns appear to have pervasive effects on our social functioning' (Fairbairn \& Sayette 2014: 1371). Dat het specifiek de inhoud van de betreffende mentale toestanden is waaraan causaal effect wordt toegeschreven, wordt duidelijk doordat de veronderstelde causale verbanden nooit willekeurig zijn ('zorgen over afwijzing beïnvloeden de hoeveelheid gegeten asperges'). Er bestaat altijd een duidelijk logische relatie tussen de veronderstelde mentale oorzaak (zorgen over afwijzing) en het verwachte effect (geremd sociaal gedrag). Zorgen over afwijzing worden geacht bepaalde effecten te hebben (op sociaal gedrag) en andere effecten niet te hebben (op het eten van asperges), vanwege hun inhoud (het feit dat de zorgen over afwijzing gaan).

Hoewel mentale inhoud en mentale veroorzaking dus centrale begrippen lijken te zijn in de empirische psychologie, is er binnen de discipline vrijwel geen discussie over de vraag wat het eigenlijk betekent om mentale toestanden te hebben, of hoe de inhoud van onze gedachten en emoties causaal effect zou kunnen hebben. Er bestaat natuurlijk veel filosofische literatuur over deze onderwerpen, zowel in de philosophy of mind alsook in de filosofie van de psychologie - maar deze discussies zijn volledig losgezongen van de dagelijkse empirische praktijk. Mijn stelling is dat dit een kwalijke zaak is, omdat het juist voor het doen van psychologisch onder- 
zoek van essentieel belang is een expliciete opvatting te hebben over hoe we mentale inhoud en mentale veroorzaking moeten begrijpen. Het belangrijkste argument daarvoor heeft te maken met de vraag hoe je mentale toestanden kunt meten. Meten is immers een cruciaal aspect van empirisch onderzoek.

Het merendeel van de psychologische studies meet mentale toestanden als overtuigingen of angsten door middel van vragenlijstonderzoek. Respondenten krijgen vragen voorgelegd als 'Heeft u vaak gedachten over X?' of 'Bent $u$ wel eens bang voor $Y$ ?' en antwoorden daarop door een punt op een bepaalde schaal aan te geven. Deze methode is dus een vorm van zelfrapportage. Hoewel veel gebruikt, wordt deze methode ook sterk bekritiseerd. Eén probleem is de rol van suggestie. De manier waarop de vraag wordt gesteld en zelfs het feit op zich dat de vraag wordt gesteld, lijkt zelf een sturend effect te hebben (Rassin 2013; Schwarz 1999). Met andere woorden, het antwoord dat mensen geven op de vraag of ze vaak bang zijn voor de dood, wordt waarschijnlijk beïnvloed door het feit dat ze hierover ondervraagd worden. Maar nog los van dit soort specifieke verstorende invloeden, hoe goed weten mensen überhaupt wat ze zelf vinden, en wat hun wensen en angsten precies zijn? Juist de geschiedenis van de psychologie (eerst via Freud, en meer recentelijk aan de hand van empirische literatuur over onbewuste processen, zie bijv. Bargh \& Chartrand 1999) leert ons dat ons zelfinzicht allesbehalve volmaakt is. Dit soort overwegingen hebben geleid tot de ontwikkeling van methoden om zogenaamde impliciete attitudes te meten (Greenwald \& Banaji 1995). Een bekend onderzoeksveld is de studie van impliciete vooroordelen, waar op indirecte manier wordt onderzocht wat voor angsten en oordelen we hebben over bijvoorbeeld etnische minderheden of homoseksuelen (Greenwald \& Krieger 2006). Vaak worden respondenten in dit soort onderzoek geprimed met stimuli die gerelateerd zijn aan het object waarover onze attitude wordt onderzocht (bijvoorbeeld de woorden 'zwart', 'Harlem', 'jazz'). Het idee is dat deze priming de onderzochte attitudes activeert. Vervolgens wordt respondenten bijvoorbeeld gevraagd in hoeverre ze een bepaald gezicht als vijandig beoordelen (Devine 1989). Uit het feit dat respondenten een gezicht als meer vijandig beoordelen als ze geprimed zijn met het sterotype van de 'zwarte Amerikaan', concluderen de onderzoekers dat mensen (impliciete) negatieve oordelen herbergen over deze bevolkingsgroep.

Deze methode roept echter de vraag op: op welke gronden kunnen we aannemen dat dit ons betrouwbare inzichten in onze overtuigingen en emoties geeft? De manier waarop impliciete attitudes worden gemeten 
veronderstelt een idee over hoe we dit soort attitudes moeten begrijpen. Blijkbaar zijn het processen die zowel in een 'actieve' als een 'slapende' stand kunnen staan (ze moeten immers eerst via priming 'geactiveerd worden'), en wier effect op de een of andere manier 'uitstraalt' naar andere oordelen die er eigenlijk niets mee te maken hebben ('hoe vijandig vindt $\mathrm{u}$ dit gezicht?'). Het meten van dat andere oordeel verloopt overigens weer op de traditionele manier - via zelfrapportage - met alle problemen van dien.

Dit brengt me tot het algemenere punt dat aan de basis ligt van mijn onderzoeksproject. Om te weten hoe je overtuigingen, emoties en andere mentale toestanden met inhoud en hun effecten kunt meten, moet je eerst begrijpen wat het is dat je probeert te meten. Om die reden is het juist voor de empirische psychologie van belang om na te denken over wat mentale toestanden zijn, hoe deze toestanden een specifieke inhoud kunnen hebben en hoe die inhoud causaal relevant kan zijn.

In mijn project wil ik op deze vragen een empirisch bruikbaar antwoord ontwikkelen. Zoals gezegd kan ik daarvoor voortbouwen op een grote hoeveelheid bestaande filosofische literatuur. Veel van deze literatuur is echter niet goed toepasbaar ten behoeve van methodologische vernieuwing in de psychologie. Uit het werk van bijvoorbeeld Davidson (2001) of Kim (1998) volgen weliswaar antwoorden op de vraag hoe we over mentale veroorzaking zouden moeten denken, maar geen concrete suggesties met betrekking tot de vraag hoe we mentale toestanden zouden kunnen meten, of hoe causale verbanden tussen toestanden aan te tonen zijn. Om dit soort toepassingen te kunnen ontwikkelen, wil ik in mijn onderzoek bepaalde discussies uit de philosophy of mind combineren met wetenschapstheoretische en methodologische inzichten. Door wijsgerige posities uit verschillende vakfilosofische discussies met elkaar in verband te brengen, denk ik te kunnen komen tot een theorie van mentale veroorzaking die zowel filosofisch interessant als ook empirisch bruikbaar is. In de volgende paragrafen zal ik laten zien in welke richting ik deze ideeën wil ontwikkelen.

\section{$2 \quad$ Psychiatrische symptomen}

Binnen het project zal ik me niet bezighouden met intentionele mentale toestanden in het algemeen, maar specifiek met die mentale toestanden die een rol spelen in empirisch onderzoek naar psychiatrische symptomen. Ik kijk dus bijvoorbeeld naar intentionele angsten (angsten over hoogten, over spinnen, over besmetting) en naar bepaalde overtuigingen (dat men 
achtervolgd wordt, dat men het gas niet heeft uitgedraaid, dat overal ziektekiemen op de loer liggen). Ik heb voor dit domein van onderzoek gekozen omdat ik meen dat juist hier conceptuele en methodologische verheldering van cruciaal belang is. Empirisch onderzoek naar emoties en overtuigingen van mensen met psychiatrische problemen wordt immers niet alleen ingegeven door academische interesse, maar ook of misschien zelfs vooral door de zoektocht naar mogelijkheden voor behandeling en herstel. De hoop is dat onderzoek ons inzicht kan bieden in de vraag hoe dysfunctionele emoties en overtuigingen kunnen worden veranderd. Met andere woorden, het is de bedoeling dat het onderzoek zinvol kan worden toegepast in de klinische praktijk. Juist vanwege dit praktische belang van empirisch onderzoek naar psychiatrische symptomen, is het mijns inziens cruciaal om beter te begrijpen wat toestanden als angsten en overtuigingen eigenlijk zijn. Heeft het bijvoorbeeld voor een therapeut zin om waanideeen te bestrijden door deze samen met de patiënt te analyseren en de patiënt te laten zien hoe onredelijk de waanideeën zijn? Om een antwoord op zo'n vraag te geven moet je eerst een idee hebben van wat een overtuiging eigenlijk is.

\section{Een theorie van mentale toestanden en mentale veroorzaking}

In mijn project wil ik het interpretivisme nieuw leven inblazen. Interpretivisme is een filosofische traditie in het denken over mentale toestanden die op dit moment een kwijnend bestaan leidt. Dat is niet zonder reden en de belangrijkste reden is dat algemeen wordt verondersteld dat het interpretivisme geen ruimte biedt voor mentale veroorzaking. Ik wil laten zien dat dat verwijt weliswaar terecht kan worden gemaakt ten aanzien van bepaalde klassieke interpretivisten (met name Daniel Dennett), maar dat het geenszins noodzakelijk volgt uit interpretivisme an sich. Tegen de gangbare opvatting in ben ik van mening dat vooral het interpretivisme van Donald Davidson en diens idee van anomalous monism een vruchtbare notie van mentale veroorzaking kunnen bieden, zolang men bepaalde cruciale theoretische aanpassingen doet. Mijn doel is om te laten zien dat een herziene vorm van interpretivisme veel van de problemen zoals die zich voortslepen in andere tradities weet te vermijden en dat deze manier van denken over mentale toestanden en mentale veroorzaking bovendien empirisch beter bruikbaar is dan andere benaderingen.

Wat zijn nu de uitgangspunten van het interpretivisme? Binnen deze 
traditie worden intentionele mentale toestanden begrepen als elementen van een toeschrijvingspraktijk. Emoties, wensen en overtuigingen met inhoud zijn beschrijvingen die we gebruiken om het gedrag van anderen (en indirect ook dat van onszelf) beter te kunnen voorspellen en verklaren (Dennett, 1987). Als ik zeg 'Jan is bang voor spinnen', dan probeer ik er met die uitspraak voor te zorgen dat we Jans gedrag (het feit dat hij de kamer uitrent als hij een spin ziet) en zijn uitspraken ('Iiieeehh... Een spin!!') beter kunnen begrijpen. Ik verwijs met de uitspraak 'Jan is bang voor spinnen' niet naar een interne toestand in Jans hoofd (zoals een representatie van het zinnetje ('Ik ben bang voor spinnen'). De inhoud van mentale toestanden, dus het feit dat Jans angst over spinnen gaat, moet volgens deze traditie dan ook worden gezien als een aspect van mijn beschrijving en niet als iets dat zich in Jans hoofd zou moeten bevinden.

Een voor de hand liggende tegenwerping is: maar het is toch duidelijk Jan die bang voor spinnen is? Als hij dat niet zou zijn, hoe zou mijn beschrijving dan voorspellende of verklarende waarde kunnen hebben? Natuurlijk ontkent het interpretivisme niet dat mensen psychologische toestanden hebben die kunnen worden beschreven als 'angst voor spinnen'. Het punt is dat psychologische toestanden alleen intentionele inhoud hebben voor zoverre ze worden beschreven. Intentionele inhoud kan alleen binnen een talige context bestaan (Davidson, 1984). ${ }^{1}$ Dat betekent dat de psychologische toestand van Jan pas een angst wordt die over spinnen gaat, wanneer mensen met talige vermogens zo'n toestand op die manier gaan beschrijven. Dit hoeven overigens niet alleen 'anderen' te zijn. Aangezien Jan ook zelf deel uitmaakt van deze talige praktijk, zal hij zijn eigen psychologische toestanden ook in intentionele termen kunnen beschrijven. Het is echter misleidend om te denken dat de mogelijkheid van dit soort zelfrapportage aantoont dat de intentionele inhoud van emoties en gedachten 'in Jans hoofd' zit. Ik zal later laten zien dat dit punt van belang is voor de vraag hoe mentale toestanden het best gemeten kunnen worden in empirisch onderzoek.

Het aantrekkelijke van het interpretivisme is dat het afrekent met het probleem dat er binnen de traditionele metafysica geen plaats lijkt te zijn voor mentale inhoud (ofwel voor mentale eigenschappen, voor een overzicht zie Heil \& Mele (1995) en Kim (1998)). Deze kwestie vormt al decen-

1 Hier bouwt de interpretivistische traditie voort op het werk van Chisholm (1957) en Quine (1960); hiertegenover staan naturalisten zoals Dretske (1995) en Millikan (1984) die trachten aan te tonen dat intentionaliteit ook in een niet-talige context kan bestaan. 
nia het zwaartepunt van de filosofische discussie over mentale inhoud, waarbij het nog altijd de vraag is of het mogelijk is om met succes tussen de Scylla van het dualisme en de Charybdis van het epifenomenalisme door kan laveren. ${ }^{2}$ Het interpretivisme doorbreekt deze patstelling door te stellen dat mentale inhoud helemaal niet in metafysische termen moet worden begrepen.

Dit punt verklaart echter ook meteen waarom het interpretivisme geen populaire positie is. Want als de inhoud van psychologische toestanden alleen maar een aspect van de beschrijving ervan is, hoe kan mentale inhoud dan causaal effect hebben? Causaliteit is een metafysische notie, en het interpretivisme biedt nu juist een niet-metafysische notie van mentale inhoud. In mijn project wil ik laten zien hoe mentale veroorzaking kan worden begrepen binnen een interpretivistisch denkkader. Mijn voorstel is om mentale toestanden te zien als toeschrijvingen van een bepaald patroon in gedrag, expressie (verbaal en non-verbaal), cognitieve en overig-lichamelijke processen en subjectieve ervaring. Dus wanneer we Jan een angst voor spinnen toeschrijven, schrijven we Jan daarmee een patroon toe van bepaald gedrag (wegrennen), expressie ('Iiieeehh... Een spin!', maar ook bepaalde gezichtsuitdrukkingen en lichaamshoudingen), lichamelijke processen (zoals een bepaalde focus van de aandacht, maar ook bijv. fysiek verkrampen) en subjectieve ervaringen (hoe het voor Jan voelt wanneer hij een spin ziet). De elementen van dit patroon hebben causaal effect: ze hebben invloed zowel op Jan zelf alsook op zijn omgeving. ${ }^{3}$ Maar, de causale rol van zulke patronen bestaat niet in virtue of content. Het patroon dat Jan vertoont gaat nergens over. Intentionele inhoud ontstaat pas wanneer zo'n patroon wordt beschreven en toegeschreven in een talige praktijk. ${ }^{4}$

2 Het probleem hier is dat ofwel de conclusie dreigt dat de traditionele metafysica niet toereikend is en dat mentale eigenschappen een niet-fysieke vorm van materialiteit bezitten (dualisme) - ofwel dat mentale eigenschappen zelf niets 'doen' in de materiële wereld, maar dat hun causale vermogens afgeleid zijn van de vermogens van niet-mentale eigenschappen (epifenomenalisme).

3 Hier zal men zich direct afvragen: hebben subjectieve ervaringen (ofwel qualia) ook causaal effect? Maar hoe dan? Het probleem van mentale veroorzaking ligt hier direct weer op de loer. Ik zal op dit punt beargumenteren dat aangezien subjectieve ervaringen wel degelijk een materiële basis hebben, ze ook causaal effectief kunnen zijn, alleen niet 'in virtue of their content'.

4 De visie die ik wil ontwikkelen ligt het dichtst bij dispositionele visies zoals bijvoorbeeld die van Eric Schwitzgebel (2002). Ook Schwitzgebel stelt dat mentale toestanden moeten worden begrepen in termen van patronen. Het verschil tussen zijn visie en de interpretationistische visie die ik wil ontwikkelen, is dat Schwitzgebel meent dat deze patronen wél een inhoud kunnen hebben. 
De laatste stap in mijn project zal gaan om deze vraag: hoe zou je mentale toestanden, op deze manier begrepen, kunnen operationaliseren ten behoeve van empirisch onderzoek? En hoe kun je hun causale effecten meten? Om terug te komen op dat waarmee ik begon, de standaardmethode om mentale toestanden te meten (vragenlijstonderzoek) wordt vaak bekritiseerd omdat mensen allesbehalve volmaakt inzicht blijken te hebben in hun eigen gedachten, wensen en emoties. Mijn analyse van mentale toestanden biedt hier wellicht een interessante verklaring voor. Volgens zo'n analyse zijn overtuigingen geen 'zinnetjes in je hoofd' die je alleen maar hoeft af te lezen om erachter te komen wat je denkt. Wat je denkt manifesteert zich in wat je zegt, hoe je kijkt, wat je doet en wat je ervaart. En, wat je denkt wordt pas in propositionele termen ('Ik denk dat X') uitgedrukt in een proces dat niet moet worden gezien als directe rapportage, maar als een talige vorm van (zelf)interpretatie.

Om te begrijpen hoe mentale toestanden causaal effect kunnen hebben, moeten psychologen zich dus niet richten op talige interpretaties als ('Ik denk dat X'), maar op de patronen van psychologische processen waarnaar deze talige interpretaties verwijzen. Dat betekent dat psychologen patronen van gedrag, expressies, processen en subjectieve ervaringen moeten gaan meten, en dat ze inzicht moeten verwerven in causaliteit in netwerken. Voor dit deel van het project zal ik samenwerken met de onderzoeksgroep van Prof. Denny Borsboom aan het Departement Psychologie van de UvA, die al enkele jaren bezig is met het modelleren van netwerken van psychologische verschijnselen (Cramer et al. 2012; Schmittmann et al. 2013).

\section{$4 \quad$ Implicaties}

Zoals gezegd zal ik me specifiek richten op mentale toestanden die een rol spelen bij psychiatrische problemen, omdat het juist in de klinische praktijk belangrijk is om beter inzicht te krijgen in de vraag wat wensen, overtuigingen en emoties precies zijn. Dus hoe zou mijn analyse kunnen bijdragen aan beter begrip van psychiatrische symptomen?

Ten eerste denk ik dat een interpretivistische visie op mentale toestanden interessante implicaties heeft voor ons begrip van bijvoorbeeld waanideeën. Op basis van het interpretivisme zouden we waanideeën moeten begrijpen als talige zelfinterpretaties van een onderliggend patroon van processen, gedragingen, expressies en subjectieve ervaringen. Wanneer iemand een waanidee heeft als 'ik geloof dat ik word afgeluisterd door de 
CIA' zouden er twee dingen aan de hand kunnen zijn. Ten eerste zou het probleem kunnen liggen op het niveau van het onderliggende patroon. Misschien hebben sommige mensen afwijkende ervaringen, expressies en processen die vervolgens tot de meest logische interpretatie leiden ('ik geloof dat ik word afgeluisterd door de CIA'). Ten tweede zou het probleem kunnen liggen in de talige zelfinterpretatie zelf. Mogelijk interpreteren sommige mensen hun eigen ervaringen, expressies en processen op een verkeerde manier. Welke de juiste analyse is, zou empirisch onderzoek kunnen uitwijzen.

Een tweede punt is dat de vraag hoe je mentale toestanden kunt veranderen, op basis van mijn interpretivistische analyse een heel ander antwoord krijgt. Een overtuiging als 'ik geloof dat ik word afgeluisterd door de CIA' is niet een zinnetje in iemands hoofd, dat je op basis van rationele argumenten probeert te vervangen door een ander zinnetje. Het is een toeschrijving die verwijst naar een heel patroon van processen, gedragingen en ervaringen. Dat betekent dus dat om een overtuiging te veranderen een heel patroon veranderd moet worden, en dat het niet vanzelfsprekend is dat rationele argumenten daarbij een grote rol zouden moeten spelen.

\section{Bibliografie}

Bargh, J.A., en Chartrand, T.L. (1999) The unbearable automaticity of being. American Psychologist 54(7), pp. 462-79.

Brentano, F. (1874) Psychologie vom Empirischen Standpunkt. Erste und einziger Band. Leipzig: Meiner.

Chisholm, R. (1957) Perceiving. Ithaca, NY: Cornell University Press.

Cramer, A.O., Sluis, S., Noordhof, A., Wichers, M., Geschwind, N., Aggen, S.H., ..., en Borsboom, D. (2012). Dimensions of normal personality as networks in search of equilibrium: You can't like parties if you don't like people. European Journal of Personality 26(4), pp. 414-431.

Davidson, D. (1984) Inquiries into Truth and Interpretation. Oxford: Clarendon Press.

Davidson, D. (2001) Essays on Actions and Events. Oxford: Oxford University Press.

Dennett, D.C. (1987) The Intentional Stance. Cambridge: MIT Press.

Devine, P.G. (1989) Stereotypes and prejudice: their automatic and controlled components. Journal of Personality and Social Psychology 56(1), pp. 5-18.

Dretske, F. (1995) Naturalizing the Mind. Cambridge, Mass.: MIT Press.

Fairbairn, C.E., en Sayette, M.A. (2014). A social-attributional analysis of alcohol response. Psychological Bulletin 140(5), pp. 1361-1382.

Gildersleeve, K., Haselton, M.G., en Fales, M.R. (2014) Do women's mate preferences change across the ovulatory cycle? A meta-analytic review. Psychological Bulletin 140(5), pp. 12051259 .

Greenwald, A.G., en Banaji, M.R. (1995) Implicit social cognition: attitudes, self-esteem, and stereotypes. Psychological Review 102(1), pp. 4-27. 
Greenwald, A.G., en Krieger, L.H. (2006) Implicit bias: Scientific foundations. California Law Review 94, pp. 945-967.

Heil, J., en Mele, A.R. (red.) (1995) Mental Causation. Oxford: Oxford University Press.

Kim, J. (1998) Mind in a Physical World. Cambridge, MA: MIT Press.

Millikan, R.G. (1984) Language, Thought and Other Biological Objects. Cambridge, Mass.: MIT Press.

Quine, W.V.O. (1960) Word and Object. Cambridge, Mass.: MIT Press.

Rassin, E. (2004) De waarde van het woord. Over het belang van zelfrapportages voor de psychologie. Psycholoog 39(1), pp. 10-16.

Schmittmann, V.D., Cramer, A.O., Waldorp, L.J., Epskamp, S., Kievit, R.A., en Borsboom, D. (2013) Deconstructing the construct: A network perspective on psychological phenomena. New Ideas in Psychology 31(1), pp. 43-53.

Schwarz, N. (1999) Self-reports: how the questions shape the answers. American Psychologist 54 (2), pp. 93-105.

Schwitzgebel, E. (2002) A phenomenal, dispositional account of belief. Nous 36, pp. 249-275.

Searle, J. (1983) Intentionality. Cambridge: Cambridge University Press.

\section{Over de auteur}

Annemarie Kalis is universitair docent aan het Departement Filosofie en Religiewetenschap van de Universiteit Utrecht. Ze heeft een dubbele achtergrond in de psychologie en de wijsbegeerte, en doet onderzoek op het gebied van handelingstheorie, ethiek, en filosofie van de psychologie en psychiatrie. In 2014 ontving ze een NWO-VENI subsidie. Een aantal publicaties: Failures of agency. Irrational behavior and self-understanding. Lanham: Lexington Books; Kalis A, Kaiser S, \& Mojzisch A (2013). Why we should talk about option generation in decision-making research. Frontiers in Psychology 4:555, 1-8; Kalis A \& Meynen G (2014). Mental disorder and legal responsibility: The relevance of stages of decision-making. International Journal of Law and Psychiatry, Epub ahead of print, DOI 10.1016/ j.ijlp.2014.02.034. 